\title{
Latent pre-excitation: exposure of anterograde accessory pathway conduction during atrial fibrillation
}

Sir,

Robinson et al (1988;59:53-5) have described three patients with "latent pre-excitation".' During sinus rhythm there was no delta wave, whereas during atrial fibrillation there apparently was considerable pre-excitation. All three cases had a left lateral accessory pathway. It is therefore quite understandable for Robinson et al to seek to explain this interesting phenomenon in terms of the location of the accessory bundle.

Milstein $e t a l^{2}$ have recently reported that patients with the Wolff-Parkinson-White syndrome and those with enhanced conduction in the atrioventricular node who were matched for anterograde refractory period showed similar ventricular rates during atrial fibrillation. They had expected a slower ventricular response when conduction through the atrioventricular node was enhanced because of a greater propensity for concealed conduction. We found ${ }^{3}{ }^{4}$ that all anterograde conduction was blocked when patients with atrial fibrillation had right ventricular pacing at intervals that were twice as long as the shortest RR intervals without such pacing.

Comparative studies of the mammalian atrioventricular conduction system ${ }^{5-7}$ show a mismatch between heart size and atrioventricular conduction time, with small mammals having relatively long PR intervals and large mammals relatively short atrioventricular transmission times. Both observations led us to question ${ }^{8}$ the traditional concepts of atrioventricular conductivity - that is that the atrial impulse is conducted slowly through the atrioventricular node and at high speed through the HisPurkinje system to the ventricles.

We cannot be certain who introduced the concept of atrioventricular conduction. ${ }^{9}$ Certainly, nobody has ever proved that the atrial impulse that leaves the atrioventricular node is the same one that enters it. We suggested that continuous overdrive suppression of the automaticity of the atrioventricular node may explain anterograde block during right ventricular pacing and atrial fibrillation. ${ }^{4}$ In other words, during atrial fibrillation (without right ventricular pacing) there may be no atrioventricular conduction, but rather automaticity of the atrioventricular node and random electrotonic modulation of phase 4 of the atrioventricular nodal pacemaker. ${ }^{10}$ If automaticity of the atrioventricular node can undergo overdrive suppression by retrogradely conducted ventricular impulses, in principle impulses reaching the atrioventricular node from the atrial direction could have the same effect. Atrioventricular transmission during sinus rhythm would then not be caused by actual conduction of the atrial impulse through the atrioventricular node and the His-Purkinje system, but by a continuous resetting of the pacemaker of the atrioventricular node entrainment by the successive atrial excitation waves, followed by conduction through the His-Purkinje system. ${ }^{11}$ Concealed conduction of atrial extrasystoles can be explained on the basis of hyperpolarisation of the pacemaker cell during phase 4 of the monophasic action potential. Overdrive suppression and resetting of the pacemaker of the atrioventricular node does not need to take much more time in large atrioventricular nodes than in the smaller ones. This may explain the relatively short PR intervals in the larger mammals."

The enhanced atrioventricular conduction described by Milstein $e t a l^{2}$ could be caused by enhanced automaticity of the pacemaker of the atrioventricular node, for whatever reason; this would be hard to modulate by atrial fibrillation. The propensity for concealed conduction during atrial fibrillation, according to our theory, depends on the rate of rise of phase 4 depolarisation of this suggested atrioventricular pacemaker and the capacity of the atrial impulses that reach the atrioventricular node to modulate this depolarisation. So in patients with accessory pathways and atrial fibrillation transmission of the atrial impulses by the accessory pathway rather than by the normal atrioventricular transmission system would also depend on the rate of rise of diastolic depolarisation of the pacemaker of the atrioventricular node. From the moment impulse propagation occurs via the accessory pathways during atrial fibrillation, it is quite likely that concealed retrograde overdrive suppression of automaticity may take place, sealing off the atrioventricular node from atrial impulses. This explanation does not take into account the left sided location of the accessory bundle. The left sided site only explains the lack of 
pre-excitation during sinus rhythm, not the preference for the bypass tract during atrial fibrillation.

Thus latent pre-excitation could become apparent during atrial fibrillation if the atrioventricular node is an unprotected pacemaker that exhibits resetting during sinus rhythm and electrotonic modulation during atrial fibrillation.

F L Meijler, Interuniversity Cardiology Institute, Utrecht, The Netherlands.

\section{References}

1 Krikler DM, Rowland E. Concealed pre-excitation. J Electrocardiol 1978;11:209-11.

2 Milstein S, Klein SL, Rattes MF, Sharma AD, Yee R. Comparison of the ventricular response during atrial fibrillation in patients with enhanced atrioventricular node conduction and Wolff-Parkinson-White syndrome. J Am Coll Cardiol 1987;10:1244-8.

3 De Jongste MJL, Wittkampf FHM, Lie KI, Van der Tweel I, Meijler FL. Regularization of ventricular rhythm by right ventricular pacing in patients with atrial fibrillation [Abstract]. Circulation 1985;72:III32.

4 Wittkampf FHM, De Jongste MJL, Lie KI, Meijler FL. The effect of right ventricular pacing on ventricular rhythm during atrial fibrillation. $\mathrm{J} \mathrm{Am} \mathrm{Coll}$ Cardiol 1988;11:539-45.

5 Clark AJ. Conduction in the heart of mammals. In: Comparative physiology of the heart. Cambridge: Cambridge University Press, 1927:49-51.

6 Meijler FL. Atrioventricular conduction versus heart size from mouse to whale. J Am Coll Cardiol 1985;5:363-5.

7 Meijler FL. Comparative aspects of the dual role of the human atrioventricular node. $\mathrm{Br}$ Heart $J$ 1986;55: 286-90.

8 Meijler FL, Janse MJ. Morphology and electrophysiology of the mammalian atrioventricular node. Physiol Rev 1988;68:608-47.

9 Fye WB. The origin of the heart beat: a tale of frogs, jellyfish, and turtles. Circulation 1987;76:493-500.

10 Cohen RJ, Berger RD, Dushane TE. A quantitative model for the ventricular response during atrial fibrillation. IEEE Trans Biomed Eng 1983;30:769-81.

11 Van der Tweel I, Herbschleb JN, Borst C, Meijler FL. Deterministic model of the canine atrio-ventricular node as a periodically perturbed, biological oscillator. J Appl Cardiol 1986;1:157-73.
This letter was shown to one of the authors, whor replies as follows:

Sir,

We were aware of the interesting concepts developed by Meijler and his colleagues which have recentle been published. Their attractive hypothesis can be tested and potentially falsified, and time will telp whether it will replace current views on atrioven $\mathbb{\Omega}$ tricular conduction.

Meijler questions these classic concepts and won = ders how they were developed. There was much debate on this question at the turn of the century $\frac{\vec{\omega}}{\vec{\omega}}$ and when Mackenzie formulated his ideas on the clinical aspects of conduction of the atrial impulse to the ventricles he based them substantially on the fundamental work of Gaskell, Keith, and Kent in England and on the observations of Engelmann of Utrecht and Wenckebach, then of Groningen. ${ }^{2}$ The following year Tawara described the atrioventricular node, ${ }^{3}$ and in the first edition of Mackenzie's Diseases of the heart, figure 2 shows "the Knoten of Tawara" the novel concept that conduction occurred through the atrioventricular node was considered at some length. ${ }^{4}$

Whether the physiological concept of atriovene tricular node conduction is correct, or whethes Meijler's attractive hypothesis achieves acceptarice the factors that we described in our patients witlo latent pre-excitation presumably caused the latene accessory pathway to become activated during atria $\vec{\Phi}$ fibrillation while the function of the atrioventriculap node was depressed. What we saw in our patients i not incompatible with the new hypothesis.

Dennis M Krikler,

Royal Postgraduate Medical School, London.

\section{References}

1 Burchell HB. A centennial note on Waller and the first human electrocardiogram. Am J Cardiol 198 59:979-83.

2 Mackenzie J. New methods of studying affections of the heart. I. Affections of the function of conductivity. $B \mathrm{~K}$ Med J 1905;i:519-22.

3 Tawara S. Das Reitzleitungssystem des Säugertierherzo erns. Eine anatomisch-histologische Studie über de Atrioventriculärbundel und die Purkinjeschen Fädev Jena: Verlag von Gustav Fischer, 1906.

4 Mackenzie J. Diseases of the heart. London: Henres Frowde and Hodder and Stoughton, 1908:111-6. 